\title{
New insulating material in maintenance of body temperature
}

\author{
B M HOLLAND, A R BATES, O P GRAY, J F PEARSON, AND C A J WARDROP \\ Departments of Child Health, Haematology, and Obstetrics, Welsh National School of Medicine, and \\ Department of Physics, University College, Cardiff
}

SUMMARY Flectalon, a web of aluminised polyvinylchloride fibres, has been formulated to minimise radiant heat losses and to provide conventional insulation. Critical temperature determinations were used to assess the insulating efficacy of this and other swaddling materials in infants. The critical temperature for a baby 2 to 10 days old was $31^{\circ} \mathrm{C}$ when naked and $23^{\circ} \mathrm{C}$ when wrapped in a Silver Swaddler or a sheet and two blankets. The use of a quilt made with Thinsulate or Hollofil with a mass per unit area of 160 to $180 \mathrm{~g} / \mathrm{m}^{2}$ reduced the critical temperature to $19 \cdot 5^{\circ} \mathrm{C}$, while Flectalon of comparable weight reduced the critical temperature to $13 \cdot 8^{\circ} \mathrm{C}$ : Flectalon is thus an efficient insulator.

The risk of overheating was studied by monitoring swaddled babies' rectal temperatures at various ambient temperatures. Some forms of swaddling caused increases in rectal temperatures at 'normal' hospital temperatures, implying risks from warmer environments and assessments of swaddling materials should, therefore, include medical evaluation of efficiency and safety. Flectalon merits assessment in other groups at risk from hypothermia.

Newborn infants are at risk from hypothermia. Effective swaddling, especially of sick and preterm infants, is often difficult to achieve. Heat losses by radiation are always considerable but are little reduced by current conventional methods. Flectalon, a web of vacuum aluminised polyvinylchloride fibres, developed in the Physics Department, University College, Cardiff, is formulated to minimise radiant as well as convective and conductive heat losses. Our aim in this study was to make an objective test of this material.

Determination of the critical temperature ${ }^{1}$ of newborn infants is used to compare Flectalon with various standard insulating materials. Critical temperature is defined here as the lowest environmental temperature at which an infant can maintain body core temperature without showing an increased oxygen consumption. Insulation, by conserving body heat, will result in a lowering of the environmental temperature at which the body must start to increase oxygen consumption to maintain core temperature, that is insulation lowers the critical temperature. ${ }^{2}$ Measurement of critical temperature, therefore, provides a useful physiological means of assessing insulating efficiency. An assessment has also been made of the risk of overheating-a potential danger in well swaddled babies nursed in warm environments. ${ }^{34}$

\section{Patients and methods}

Normal term babies aged 2 to 10 days were studied. Parental consent and appropriate ethical committee approval had been given. To determine the critical temperature, oxygen consumption was measured by an open circuit method ${ }^{5}$ which gives a minimal oxygen consumption of mean (SD) $6.52(0.90) \mathrm{ml} / \mathrm{kg} / \mathrm{min}$. In estimating the critical temperature we measured oxygen consumption repeatedly during a progressive fall in environmental temperature at $1^{\circ} \mathrm{C}$ intervals. A sustained rising trend in oxygen consumption with an initial minimum rise of $2 \mathrm{ml} / \mathrm{kg} / \mathrm{min}$ indicated the critical temperature. Oxygen consumption measurements were made at at least $2^{\circ} \mathrm{C}$ below the estimated critical temperature, and then for confirmation were repeated at 1 to $2^{\circ} \mathrm{C}$ above the estimated temperature. Continuous rectal temperature monitoring showed falling trends at environmental temperatures below the estimated critical temperature, supporting these estimations. The measurements were started one hour after feeding in babies in rapid eye movement sleep or quietly awake. 
We studied naked (control) infants and babies (wearing only disposable napkins) swaddled in various materials, nursed in an unhumidified Vickers 59 incubator which had been modified to control temperatures over the $10^{\circ} \mathrm{C}$ to $37^{\circ} \mathrm{C}$ range. The operative environmental temperature was calculated and employed. Specially designed sleeping bags with hoods (Fig. 1) were made, incorporating Flectalon, Hollofil (a polyester hollow fibre, ICI), and Thinsulate (a polyester-polyolefin microfibre, $3 \mathrm{M} \mathrm{Co}$ ) as quilted insulation. To assess the influence of aluminisation we also studied a bag quilted with non-aluminised polyvinylchloride fibres. The bags were identically constructed, both in quilting methods and outer fabrics. The Flectalon bags were constructed using web from four different production speeds, with mass per unit area in the range 70 to $220 \mathrm{~g} / \mathrm{m}^{2}$; the Hollofil and Thinsulate bags were constructed using commercially available wadding with mass per unit area of $160 \mathrm{~g} / \mathrm{m}^{2}$ and 180 $\mathrm{g} / \mathrm{m}^{2}$ respectively. The lofts (maximum thickness of insulating material) of the $220 \mathrm{~g} / \mathrm{m}^{2}$ Flectalon and $160 \mathrm{~g} / \mathrm{m}^{2}$ Hollofil bags, and the $70 \mathrm{~g} / \mathrm{m}^{2}$ Flectalon

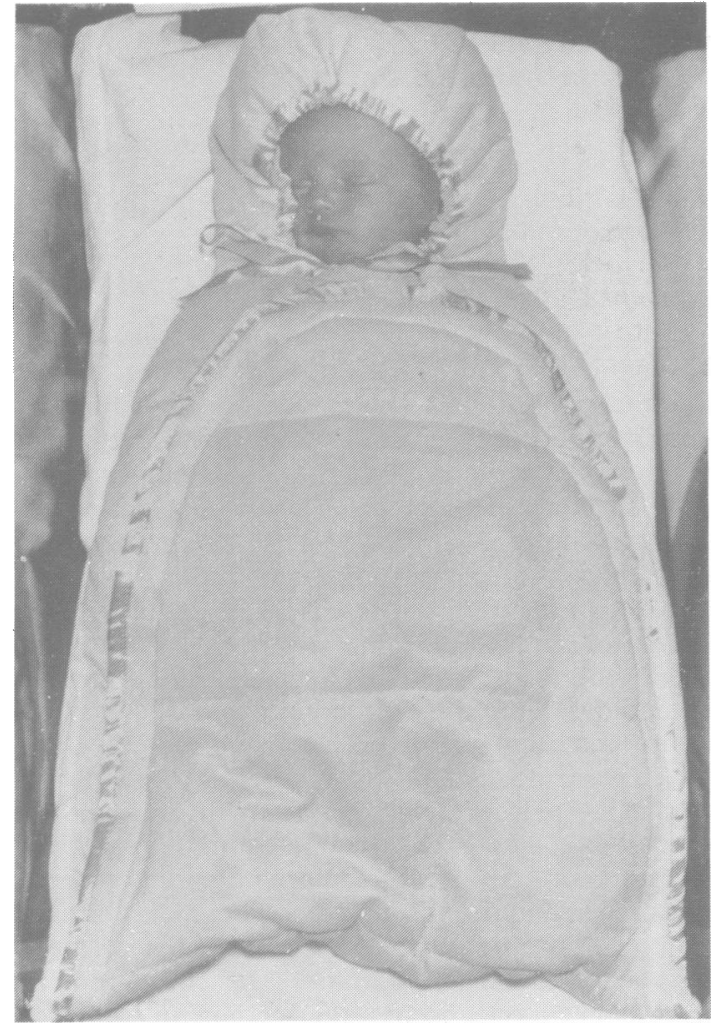

Fig. 1 Baby swaddled in test bag. and $180 \mathrm{~g} / \mathrm{m}^{2}$ Thinsulate bags were similar. These bags were compared with a conventional hospital swaddling including a fashioned helmet, a sheet and two blankets $\left(1300 \mathrm{~g} / \mathrm{m}^{2}\right)$ and the Silver Swaddler (aluminium foil) (Lewis Woolf, Griptight Ltd.), with and without single thickness gamgee (cotton wool). The observations were interrupted if infants became disturbed by the emptying of bowel or bladder.

After determining the critical temperature in different materials, we monitored rectal temperature at various environmental temperatures. For each swaddling material, the rectal temperatures of at least five babies were monitored for 90 minutes at various ambient temperatures above and below the previously-determined critical temperature for that insulating material.

The risk of hyperpyrexia was studied at room temperatures by continuous monitoring of rectal temperatures for up to eight hours.

\section{Results}

Efficiency of insulation. The critical temperature findings in relation to the various insulating materials are given in the Table which shows the superior insulating efficacy of Flectalon. There is a 'dose-response relation' between Flectalon of different weights and the effects on critical temperature.

It was found that rectal temperatures tended to fall at ambient temperatures below the critical temperature and to increase at ambient temperatures above the critical temperature. For example, the rectal temperatures of five babies swaddled in a sheet and two blankets in a cot were monitored over 90 minutes at ordinary ward temperatures. At a mean temperature of $25^{\circ} \mathrm{C}$ (range 24 to $26^{\circ} \mathrm{C}$ ) there was a slight tendency to gain heat, with a mean rise of $0.22^{\circ} \mathrm{C}$; this contrasted with a mean fall of $0.08^{\circ} \mathrm{C}$ at $22^{\circ} \mathrm{C}$ (range 21 to $23^{\circ} \mathrm{C}$ ). The critical temperature in a sheet and two blankets was $23^{\circ} \mathrm{C}$ (Table).

Similar rectal temperature monitoring either in the incubator or in the ward using Flectalon (180 $\mathrm{g} / \mathrm{m}^{2}$ critical temperature $13.8^{\circ} \mathrm{C}$ ) at environmental temperatures of $25^{\circ} \mathrm{C}$ to $13^{\circ} \mathrm{C}$ showed the same tendency above and below the critical temperature for that swaddling material.

\section{An evaluation of the risk of overheating}

To study the safety of longer term effective swaddling, rectal temperatures of babies aged 2 to 10 days swaddled in hooded bags were monitored for up to 7 hours at environmental temperatures of 22 to $24^{\circ} \mathrm{C}$. We did not allow the rectal temperatures to exceed $37 \cdot 8^{\circ} \mathrm{C}$. It became clear that most normal 
Table Critical temperature (mean (SD)) of control babies and those swaddled in various insulating materials

\begin{tabular}{|c|c|c|c|c|}
\hline Insulating material & $\begin{array}{l}\text { No of } \\
\text { patients }\end{array}$ & $\begin{array}{l}\text { Critical } \\
\text { Mean }\end{array}$ & temper & $\begin{array}{l}\text { ure }\left({ }^{\circ} \mathrm{C}\right) \\
(S D)\end{array}$ \\
\hline Naked controls & 10 & $31 \cdot 1$ & \multirow{8}{*}{$0 \cdot 22$} & $(0.45)^{*}$ \\
\hline Sheet and 2 blankets & 9 & $23 \cdot 0$ & & $(0.5)^{*}$ \\
\hline Silver Swaddler & 3 & $23 \cdot 0$ & & $0 \cdot 24$ \\
\hline Thinsulate $\left(180 \mathrm{~g} / \mathrm{m}^{2}\right)$ & 5 & $19 \cdot 5$ & & $(2 \cdot 0)^{*}$ \\
\hline Hollofil $\left(160 \mathrm{~g} / \mathrm{m}^{2}\right)$ & 5 & $19 \cdot 5$ & & $(1 \cdot 2)^{*}$ \\
\hline Non-aluminised PVC $\left(110 \mathrm{~g} / \mathrm{m}^{2}\right)$ & 4 & $18 \cdot 8$ & & $(0 \cdot 5)^{*}$ \\
\hline Flectalon $\left(70 \mathrm{~g} / \mathrm{m}^{2}\right)$ & 6 & $16 \cdot 2$ & & $(0 \cdot 7)$ \\
\hline Flectalon $\left(110 \mathrm{~g} / \mathrm{m}^{2}\right)$ & 6 & $15 \cdot 8$ & & $(0 \cdot 8)$ \\
\hline $\begin{array}{l}\text { Gamgee and Silver Swaddler } \\
\left(600 \mathrm{~g} / \mathrm{m}^{2}\right)\end{array}$ & & $14 \cdot 0$ & & $(1 \cdot 1)$ \\
\hline Flectalon $\left(180 \mathrm{~g} / \mathrm{m}^{2}\right)$ & 5 & $13 \cdot 8$ & & $(0 \cdot 3)$ \\
\hline Flectalon $\left(220 \mathrm{~g} / \mathrm{m}^{2}\right)$ & 5 & $12 \cdot 8$ & & $(0 \cdot 5)$ \\
\hline
\end{tabular}

*All values higher than in Flectalon $70 \mathrm{~g} / \mathrm{m}^{2}, \mathrm{P}<0.005$ by Student's $t$ test.

babies swaddled in Flectalon $180 \mathrm{~g} / \mathrm{m}^{2}$, or in gamgee covered with Silver Swaddler were liable to show rapid increases of core temperature when nursed under 'normal' postnatal ward conditions. Babies in gamgee covered with Silver Swaddler became very sweaty under the material. Comparisons were made with bags made with Flectalon $110 \mathrm{~g} / \mathrm{m}^{2}$, Hollofil, and Thinsulate. Although the rectal temperatures of some babies increased in these bags, the rate of rise was lower. Observations were, therefore, continued over eight hours at ambient temperatures of 24 to $28^{\circ} \mathrm{C}$ during the heatwave in July 1983 , and no inordinate rise in core temperature was seen. The mean rectal temperature was $37.4^{\circ} \mathrm{C}$ in Flectalon 110 $\mathrm{g} / \mathrm{m}^{2}, 37.4^{\circ} \mathrm{C}$ in Hollofil, and $37.3^{\circ} \mathrm{C}$ in Thinsulate. In none of the babies did rectal temperature exceed $37.7^{\circ} \mathrm{C}$. Because of the results for $110 \mathrm{~g} / \mathrm{m}^{2}$ Flectalon bags, tests were not carried out on $70 \mathrm{~g} / \mathrm{m}^{2}$ Flectalon bags.

\section{Discussion}

The determination of critical temperature is a logical, safe, objective means of assessing the efficacy of insulating materials for swaddling babies. The greater efficacy of Flectalon seems to justify its formulation. Although we did not measure radiant heat losses specifically, the superiority of the aluminised fibre (critical temperature $15 \cdot 8^{\circ} \mathrm{C}$ ) over the non-aluminised fibre (critical temperature $18 \cdot 8^{\circ} \mathrm{C}$ ) suggests that Flectalon's efficiency is enhanced by minimisation of radiant heat loss.

Our results indicate that a baby swaddled in 70 $\mathrm{g} / \mathrm{m}^{2}$ of Flectalon has a lower critical temperature $\left(16.2^{\circ} \mathrm{C}\right)$ than in the bag made with either Hollofil $160 \mathrm{~g} / \mathrm{m}^{2}\left(19 \cdot 5^{\circ} \mathrm{C}\right)$ or Thinsulate $180 \mathrm{~g} / \mathrm{m}^{2}\left(19 \cdot 5^{\circ} \mathrm{C}\right)$. The critical temperatures in Flectalon $110 \mathrm{~g} / \mathrm{m}^{2}$ and $180 \mathrm{~g} / \mathrm{m}^{2}$ are lower still at $15.8^{\circ} \mathrm{C}$ and $13.8^{\circ} \mathrm{C}$ respectively. These results contrast with measure- ments carried out by the Wool Institute Research Association which show that, in British Standard tog tests (a measurement of thermal resistance equal to 10 times the temperature difference between the two faces of the material when the peak flow is $1 \mathrm{~W} / \mathrm{m}^{2}$ ), samples of the three materials Hollofil, Flectalon and Thinsulate, each with a fixed mass per unit area of $250 \mathrm{~g} / \mathrm{m}^{2}$, had thermal resistances of $7 \cdot 1$ togs, 7.7 togs, and 3.9 togs respectively. The higher the tog value, the better the insulation. Even though the filling densities are different, there is clearly no direct correspondence between the physical and physiological measurements. The difference between the thermal efficiency of Flectalon and Hollofil is much greater in the physiological tests than in the physical test, and Thinsulate, which performed less well in the physical tests, proved better physiologically than would have been predicted. We believe the results obtained in our work are a better indication of the relative merits of the materials in actual use and suggest that direct extrapolation from a tog measurement to efficiency in keeping the body warm may be questionable. A tog measurement uses a metal plate as the source of heat and the physical situation is different in many respects from the human body. The heat production in the human body is just one element in a complex system of interrelated processes (for example transpiration, transient movements etc) which all play their part in keeping the body comfortable.

Although we made fewer measurements with the Silver Swaddler than with other insulants, our observation that it seems no more effective than conventional swaddling with sheet and two blankets is not surprising. For a surface to be effective as an insulator controlling radiation loss, its emissivity must be low. An aluminised surface has emissivity $\sim 0.05$ (compared with a black body with emissivity of 1.0 ) and is the most commonly used radiative insulator. The aluminised surface may either face towards or away from the hot body; in either orientation, however, the aluminised surface should generally be exposed to air rather than be in contact with the body which can act as a conductive path for heat flow. The Silver Swaddler we tested was aluminised on one side only and so designed that this side would be in contact with the baby. The outer surface had high emissivity (around 0.7 ) and consequently the effect of aluminisation was not fully realised. The addition of gamgee gave, as expected, an improved critical temperature, but a large increase in temperature and clear discomfort to the babies was associated with its use.

The rectal temperature findings over 90 minutes at environmental temperatures above and below the critical temperature are interesting. Above the 


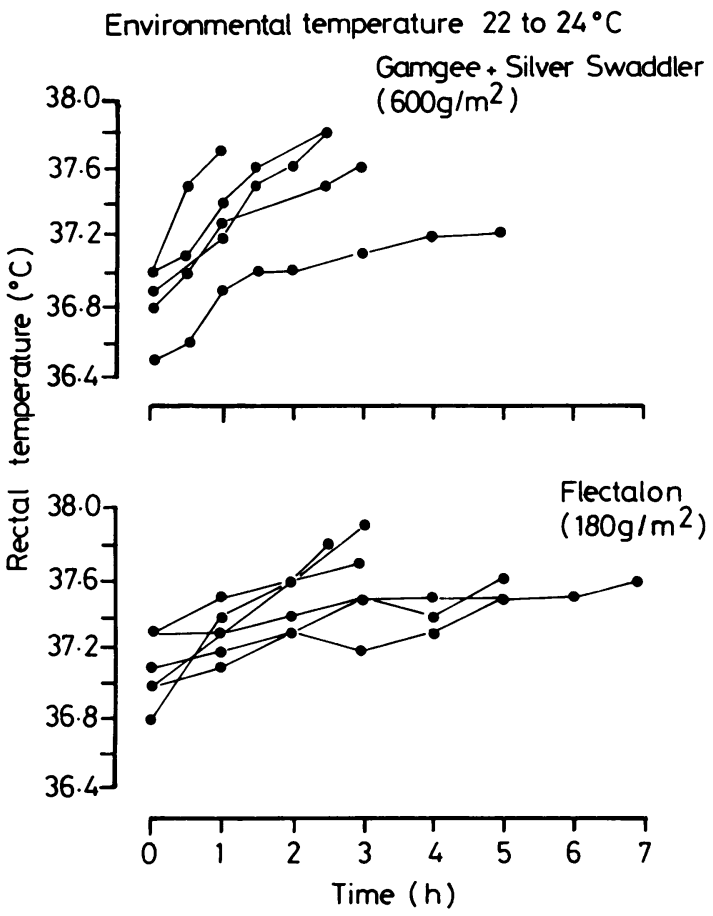

Fig. 2 Rectal temperatures of babies swaddled in Flectalon and in gamgee covered by Silver Swaddler for up to 7 hours (see text) in postnatal ward conditions.

critical temperature babies' core temperatures tended to rise; below the critical temperature the core temperature fell very slightly. Although these rectal temperature changes are not clinically important in these babies, the observations suggest that there is a narrow range of thermal neutrality in normal babies in normal ward conditions. These observations serve to validate the usefulness of the critical temperature studies in judging insulating efficiency.

The longer term rectal temperature records (Fig. 2) point to a potentially hazardous tendency for core temperatures of neonates to rise when infants are well swaddled in temperatures typical of well heated houses and hospitals. This has implications for the pathogenesis of febrile fits and in some cases sudden infant death syndrome, ${ }^{34}$ and needs further study.

Although we found Thinsulate $\left(180 \mathrm{~g} / \mathrm{m}^{2}\right)$, Hollofil $\left(160 \mathrm{~g} / \mathrm{m}^{2}\right)$, and Flectalon $\left(110 \mathrm{~g} / \mathrm{m}^{2}\right)$ safe when used to make up a sleeping bag as described in this study, they may well not be safe if the child also has clothes on, or in an older child with an appreciably higher basal metabolic rate because both these factors will reduce the critical temperature and, by implication, the safe maximum temperature. In the light of our findings we believe that medical evaluation of the efficacy and safety of new materials for infant swaddling should become mandatory.

The results of this study could reasonably be applied to other groups at risk from hypothermia and, in principle, critical temperature methods could be applied. We see great potential benefit from the use of Flectalon when high insulation is essential, for example for the elderly, for disaster victims, for unconscious patients, and for transportation of patients such as ill surgical neonates. ${ }^{6}$

Dr B Holland was funded by the Sherman Trust. We thank Miss C S Arnold, Miss E Walters, and Mrs S Knight for expert technical assistance; Mrs Fear. Sister Morris, and the Nurses of Maternity Unit. University Hospital of Wales for their help; and Miss $\mathrm{K}$ Orger for secretarial assistance.

\section{References}

1 Hill JR, Rahimtulla KA. Heat balance and the metabolic rate of new-born babies in relation to environmental temperature; and the effect of age and weight on metabolic rate. J Physiol 1965:180:239-65.

2 Hey EN. The care of babies in incubators. In: Gairdner D. Hull D, eds. Recent advances in paediatrics 4th ed. London: Churchill, 1971:180.

3 Stanton AN. 'Near-Miss' 'cot' deaths and home monitoring. $\mathrm{Br}$ Med J 1982;285:1441-2.

${ }^{4}$ Bacon CJ. Overheating in infancy. Arch Dis Child 1983;58: 673-4.

5 Evans JM, Gray OP, Holland BM, Wardrop C. Simple and versatile method for measuring oxygen consumption in infants. Arch Dis Child 1978:53:330-3.

${ }^{6}$ Spitz L, Wallis M, Graves HF. Transport of the surgical neonate. Arch Dis Child 1984;59:284-8.

Correspondence to Dr Barbara Holland, Paediatric Department, Queen Mother's Hospital, Yorkhill, Glasgow G3 $8 \mathrm{SH}$.

Received 24 May 1984 